\title{
Reaction Behavior of Coke Lump in Raceway of Blast Furnace with Pulverized Coal Injection
}

\author{
Ichiro NARUSE, Katsuya NAKAYAMA, Atsushi HIGUCHI and KHAIRIL \\ Department of Ecological Engineering, Toyohashi University of Technology, Tempaku-cho, Toyohashi 441-8580 Japan.
}

(Received on October 8, 1999; accepted in final form on April 17, 2000)

\begin{abstract}
Reaction behaviors of a coke lump in raceway of blast furnaces which pulverized coal injection technology was adopted were studied by using a horizontal pulverized coal reactor. In the experiments two types of coke lump were used as samples. In the experiments, the reaction behaviors of coke lump were continuously observed by an $8 \mathrm{~mm}$ video camera system. Mass change of the coke lump was weighed at each exposure time, and surface temperature of the coke lump was also continuously measured by a two-color pyrometer. Additionally, both the reacting coal particles and gas were sampled and analyzed, and the deposition on the coke surface was also analyzed. In order to elucidate the effect of ash particles in coal on the coke reaction, LPG was also supplied as a fuel into the reactor instead of coal.

As a result, mass loss of coke in the coal combustion is larger than that in the LPG combustion. When the coal particles collide with the coke at the surface, the ash particles easily stick there and spherical molten ash is formed on the surface. For the LPG combustion, only small spherical molten ash resulted from the coke is formed. Those results suggest that ash particles of the coal may enhance coke degradation due to chemical interactions between coal ash and coke.
\end{abstract}

KEY WORDS: iron making; coal; coke; blast furnace; pulverized coal injection.

\section{Intoroduction}

Pulverized coal injection (PCI) technology in blast furnaces has been applied since 1981 in Japan. Recently, the number of blast furnaces applying the PCI technology attains about 30 since this technology contributes to decreasing coke consumption. In order to accelerate reducing the coke consumption, it is necessary to increase coal injection rate. $^{1)}$

A number of reviews relating to the PCI technology have already been reported. For instance, Inaba ${ }^{2)}$ presented performance of the blast furnace under the condition of highrate pulverized coal injection. Shibata et al., ${ }^{3)}$ Iwanaga et $a l .{ }^{4)}$ and so forth showed distributions of both gas composition and temperature and the effect of oxygen enrichment on the combustion efficiency in the raceway. In order to improve the combustibility, Shen et al. ${ }^{5)}$ proposed the addition of $\mathrm{KMnO}_{4}$ to the coal. Kugizaki et al. ${ }^{6}$ suggested that the char structure affected reactivity of pulverized coal. Some researchers $^{7-12)}$ have also proposed a mathematical model of combustion behaviors of pulverized coal in blowpipe and raceway in the blast furnace.

For coke behaviors in the raceway of blast furnace applying the PCI technology, on the other hand, some researchers ${ }^{13-17)}$ have reported that the coke degradation in the raceway might occur due to the mechanical abrasion, thermal stress, chemical reactions and so on. Yamaguchi et $a l .{ }^{16)}$ proposed that the degradation of coke in the raceway was mainly caused by the mechanical abrasion rather than by thermal stress or thermal shock.

As found from those reviews above-mentioned, the effect of molten coal ash on the reaction and/or degradation behaviors of coke lump has not been precisely discussed yet. In this study, therefore, the reaction and/or degradation behaviors of coke lump due to ash particles of coal were elucidated experimentally by using a horizontal pulverized coal reactor with a pre-combustor to produce a high-temperature vitiated air. In the experiment, a coke lump was inserted into the furnace which coal particles were burning. In order to distinguish the effect of coal ash from the effect of other reactions such as combustion and gasification of coke, LPG was also injected into the furnace instead of the pulverized coal.

\section{Experimental}

Figure 1 shows a schematic diagram of the horizontal pulverized coal reactor with a pre-combustor employed in this study. The dimensions of the reactor are $2.1 \mathrm{~m}$ long and $0.12 \mathrm{~m}$ in inner diameter. In the pre-combustor a high-temperature vitiated air is produced by the combustion of town gas with an oxygen-enriched ambient air. The main reactor consists of two parts: the front two sections are watercooled since the particle temperature exceeds about 2000 $\mathrm{K}$, and the rear three sections are insulated by refractory to reduce the heat loss.

The coke lump is inserted at the position of $0.9 \mathrm{~m}$ apart from the coal injection point, at which the coal almost 


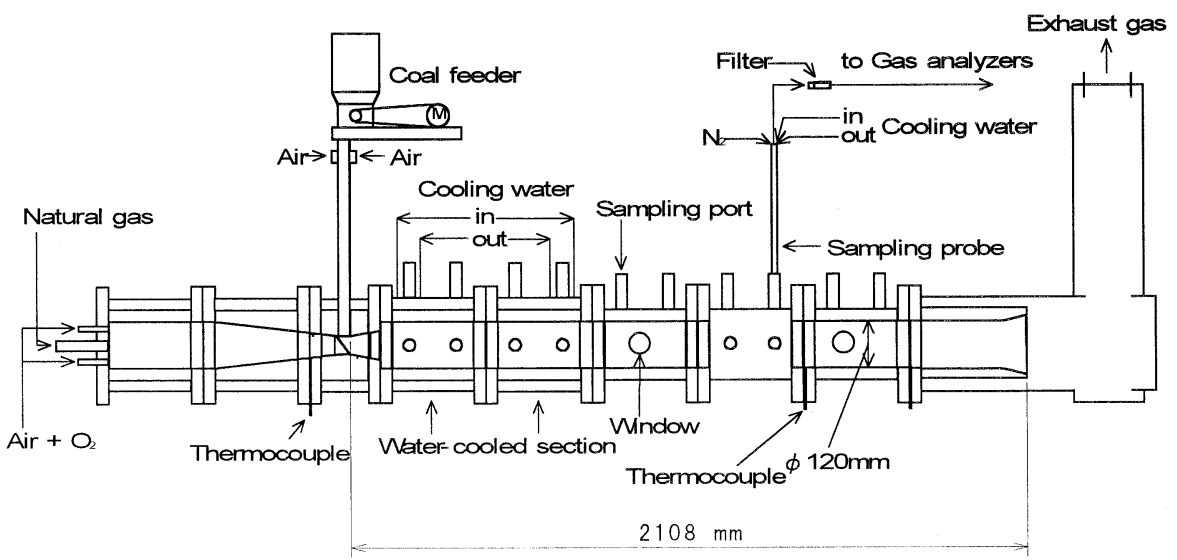

Fig. 1. Schematic diagram of horizontal pulverized coal reactor with pre-combustor.

Table 1. Properties of samples tested.

\begin{tabular}{|c|c|c|c|c|}
\hline \multicolumn{2}{|l|}{ Fuels } & KPC & Coke A & Coke B \\
\hline \multicolumn{2}{|c|}{ JIS - Reaction index (JIS K 2151.8) } & - & 10.2 & 14.7 \\
\hline \multirow{2}{*}{ Coke index $[-]$} & $\mathrm{Dl}_{150 / 15}$ & - & 84.7 & 84.0 \\
\hline & CSR & - & 71.21 & 70.10 \\
\hline \multirow{3}{*}{$\begin{array}{l}\text { Proximate analysis } \\
\text { [mass } \%, \text { dry] }\end{array}$} & Ash & 3.9 & 11.38 & 11.29 \\
\hline & VM & 44.3 & 0.78 & 0.76 \\
\hline & FC & 51.8 & 87.84 & 87.95 \\
\hline \multirow{4}{*}{$\begin{array}{l}\text { Ultimate analysis } \\
\text { [mass \%, d.a.f] }\end{array}$} & C & 78.6 & 85.74 & 86.72 \\
\hline & $\mathrm{H}$ & 5.7 & $<0.10$ & $<0.10$ \\
\hline & $\mathbf{N}$ & 0.6 & 0.65 & 0.83 \\
\hline & $\mathrm{S}$ & 1.7 & 0.47 & 0.47 \\
\hline \multirow{5}{*}{$\begin{array}{c}\text { Ash constituents } \\
\text { [mass \%, in ash, as oxide] }\end{array}$} & $\mathrm{SiO}_{2}$ & 56.24 & 53.43 & 53.06 \\
\hline & $\mathrm{Al}_{2} \mathrm{O}_{3}$ & 23.97 & 26.70 & 25.30 \\
\hline & $\mathrm{Fe}_{2} \mathrm{O}_{3}$ & 11.37 & 6.47 & 7.02 \\
\hline & $\mathrm{CaO}$ & 1.54 & 4.44 & 4.77 \\
\hline & $\mathrm{MgO}$ & 4.6 & 0.97 & 1.11 \\
\hline \multicolumn{2}{|c|}{ Ash fluid temperature $[\mathrm{K}]$} & 1623 & 1715 & 1758 \\
\hline
\end{tabular}

Table 2. Experimental conditions.

\begin{tabular}{|c|c|c|}
\hline Fuels & KPC & LPG \\
\hline Heat input [kW] & 44 & 38 \\
\hline $\mathrm{O}_{2}$ stoic. ratio [-] & 1.2 & 1.2 \\
\hline $\mathrm{O}_{2}$ conc. [vol\%] & 21 & 21 \\
\hline Vitiated air temp. [K] & 1500 & 1500 \\
\hline
\end{tabular}

burns completely, and the coal ash is also molten. Because this study tries to elucidate the interaction between the coke inserted and the molten coal ash. The burning coal particles and reaction gas are sampled at each sampling port by a water-cooled probe, at the tip which nitrogen gas is injected for dilution. For the particles sampled, the volatile matter and fixed carbon contents are analyzed by a thermobalance. The ash components in the burning coal particles are also analyzed by using a furnace-atomic absorption spectrometer (Furnace-AA). Surface temperatures of the reacting coal particle and coke are optically measured by an instantaneous two-color pyrometer. The phenomena of coke reaction are continuously observed by using an $8 \mathrm{~mm}$ video camera system. The change of coke mass during the reaction is also measured, taken out at each duration time, by using a balance. The deposition at the coke surface is also analyzed by the Furnace-AA.
$\mathrm{O}_{2}$ ratio : 1.2, $\mathrm{O}_{2}$ vol\%: 21 , Vitiated air temp. : 1500K

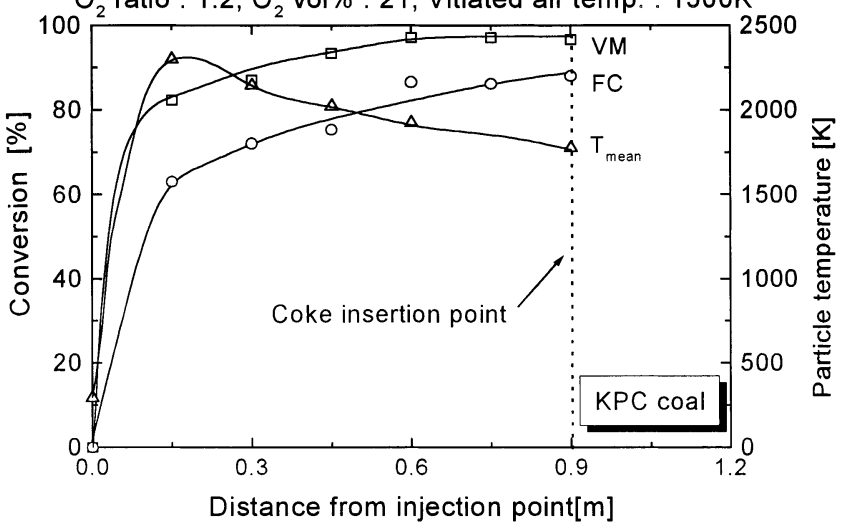

Fig. 2. Conversion of volatile matter (VM) and fixed carbon (FC) and mean particle temperature along the central furnace axis.

KPC coal was used as a sample of pulverized coal. The properties of KPC coal are shown in Table 1. KPC coal is classified as a lignite, and has low ash content and low melting temperature of ash. Two types of coke: Coke A and Coke B were used as samples, also shown in Table 1. In the table $\mathrm{DI}_{150 / 15}$ (drum index), CSR (coke strength after reaction) and JIS-reaction index denote cold strength of coke based on JIS K 2151.7, hot strength of coke and reactivity of coke based on JIS K 2151.8, respectively.

Table 2 shows the experimental conditions. The heat load is fixed at a designed value of $44 \mathrm{~kW}$ for the pulverized coal combustion. For the LPG combustion $38 \mathrm{~kW}$ of the heat load is determined, based on the conversion of pulverized coal at the insertion position of coke.

\section{Results and Discussions}

\subsection{Fundamental Reaction Behaviors}

Conversions of both volatile matter (VM) and fixed carbon (FC) and mean particle temperature along the central furnace axis in coal combustion are shown in Fig. 2. From the figure, the volatile matter is rapidly evolved as soon as coal particles are supplied into the main reactor since temperature of the vitiated air becomes high enough. The maximum of the mean particle temperature exceeds about 2250 $\mathrm{K}$ near the coal injection point which the volatile matter is burned. 


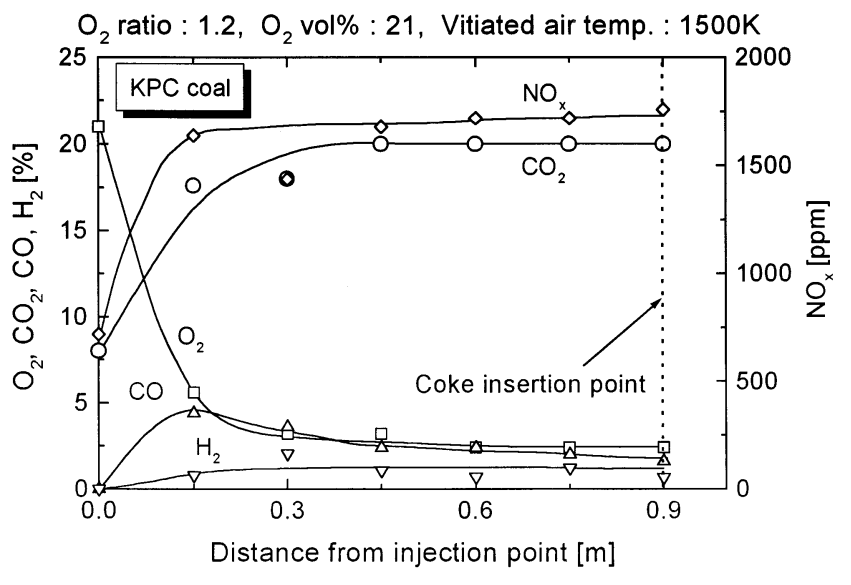

Fig. 3. Changes of gas species profiles along the central furnace axis for KPC.

$\mathrm{O}_{2}$ ratio : $1.2, \mathrm{O}_{2}$ vol\% : 21 , Vitiated air temp. : 1500K

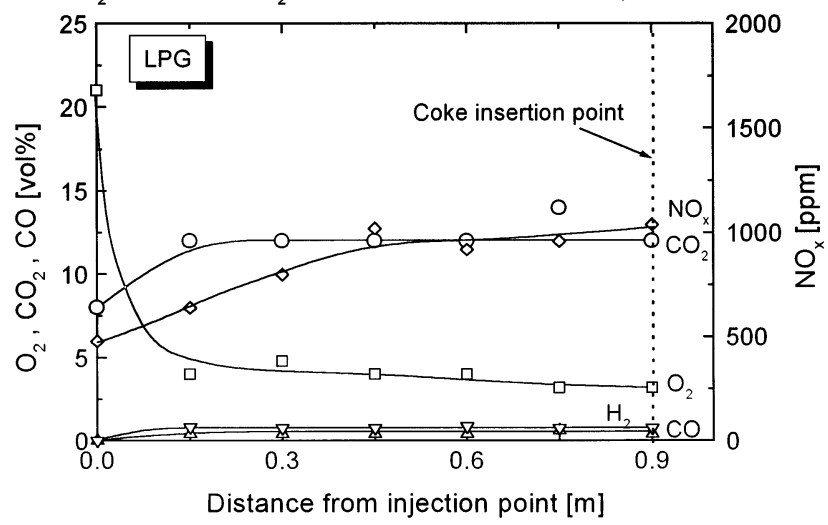

Fig. 4. Changes of gas species profiles along the central furnace axis for LPG.

Changes of the gas species concentration along the central furnace axis are shown in Fig. 3. From the figure, $\mathrm{O}_{2}$ is consumed at the same time that the volatile matter is evolved, as shown in Fig. 2, and then $\mathrm{CO}_{2}, \mathrm{CO}$, and $\mathrm{H}_{2}$ are produced simultaneously. As above-mentioned, the coke lump is inserted at about $0.9 \mathrm{~m}$ apart from the coal injection point. Evaluating the reaction atmosphere at the position of coke lump from Figs. 2 and 3, the pulverized coal is almost burned completely there, and the circumference of coke becomes weak reducing condition. Under this atmosphere the reacting particles seem to affect the coke since the coal ash is almost molten, and easily deposits on the coke surface. Water vapor concentration there is estimated to be about $15 \%$. As the mean particle temperature of coal particle attains about $1700 \mathrm{~K}$, the coal ash seems to be molten.

For the LPG combustion, on the other hand, changes of gas species concentration along the central furnace axis are shown in Fig. 4. Comparing Fig. 4 with Fig. 3, $\mathrm{CO}_{2}$ concentration for the LPG combustion is lower than that for the pulverized coal combustion, since the carbon content of LPG is lower than that of coal at the same heating value. However, the reaction gas for the LPG combustion inevitably contains higher water vapor concentration of about $23 \%$ than that for the coal combustion. $\mathrm{H}_{2}$ and $\mathrm{CO}$ concentrations for the LPG combustion are a little lower than those for the coal combustion.

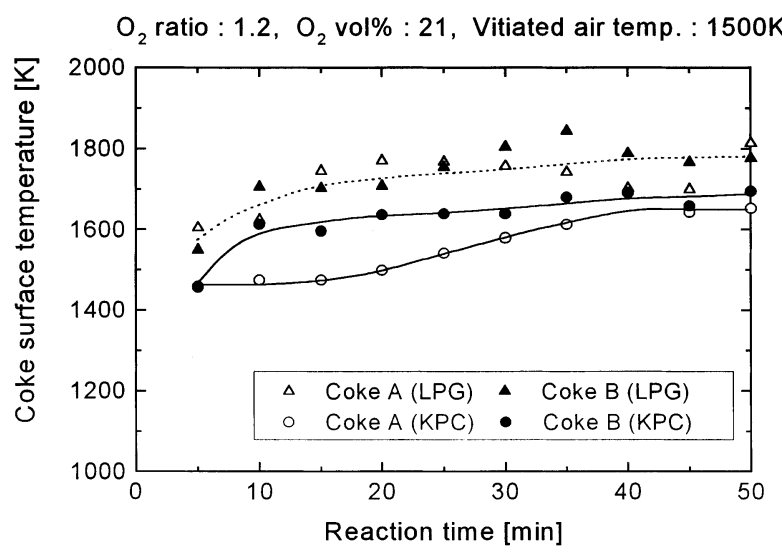

Fig. 5. Surface temperature of reacting coke lump for coal and LPG combustion.

\section{Coke A Coke B}

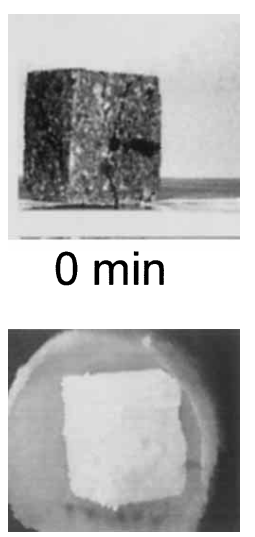

$10 \min$

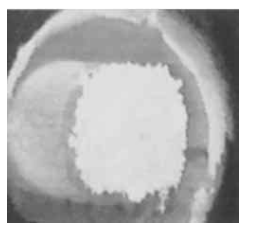

$30 \min$

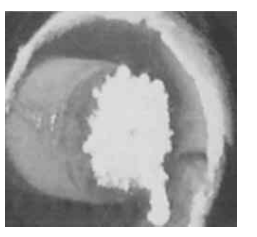

$50 \min$
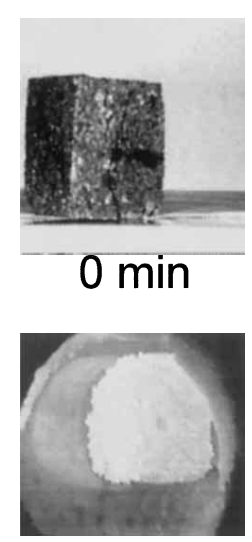

$10 \min$
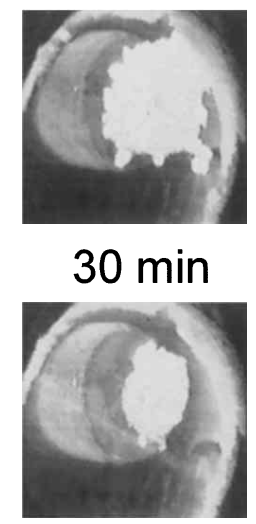

$50 \mathrm{~min}$

Fig. 6. Reaction behaviors of coke under coal combustion.

\subsection{Reaction Behaviors of Coke}

Coke surface temperature measured optically is shown in Fig. 5 for both the coal and LPG combustion. From the figure, the coke surface temperature for the coal combustion becomes a little lower than that for the LPG combustion for both the cokes. This may be caused by the influence of molten coal ash deposited on the coke surface. Comparing the difference of coke type under the coal combustion condition, the surface temperature for Coke B rises up rapidly as soon as the coke lump is inserted. This may be caused by the differences of deposition behavior and the radiative 
Coke A
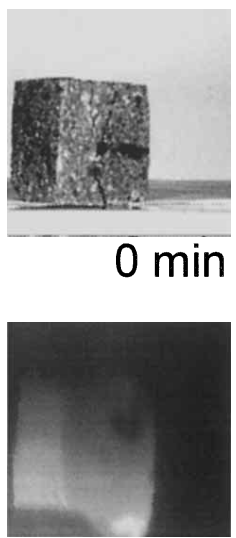

$10 \min$

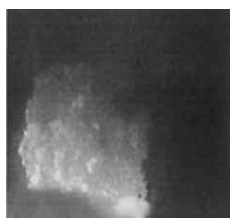

$30 \mathrm{~min}$

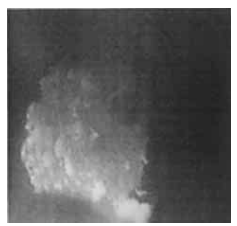

$50 \mathrm{~min}$
Coke B
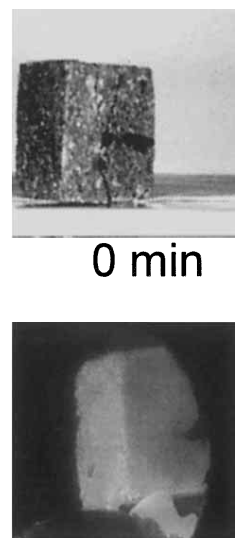

$10 \min$

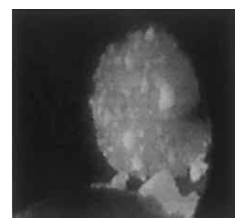

$30 \min$

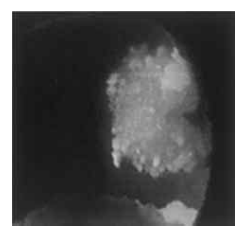

$50 \min$
Fig. 7. Reaction behaviors of coke under LPG combustion.

properties of surface due to the coal ash deposited. For the LPG combustion, on the other hand, both the temperature profiles are almost the same each other.

Coke reaction behaviors were continuously observed by using an $8 \mathrm{~mm}$ video camera system. The photos obtained are shown in Figs. 6 and 7 for the coal and LPG combustion, respectively. Comparing both the figures, shape of the coke for the coal combustion changes rapidly. Additionally, much more molten material exists on the coke surface for the coal combustion than that for the LPG combustion. Collision and deposition of the molten coal ash may cause this. Although a small amount of molten material is observed for the LPG combustion, the material on the coke surface may result from coke ash.

Figure 8 shows changes of the coke mass during the reaction for the coal and LPG combustion. Focusing on the effect of fuel type on the mass decreasing rate, the coke mass decreases faster under the coal combustion condition than that under the LPG combustion for both the cokes. In our previous study, ${ }^{18)}$ a pulverized coal particle reacted with the molten slag layer of coal ash under the gasification condition. Then, the coal particle fell in pieces. This result obtained points out that the molten coal ash can oxidize the coal. From the coal properties, as shown in Table 1, KPC coal has a high content of $\mathrm{Fe}_{2} \mathrm{O}_{3}$ in the ash. Consequently, it is guessed that $\mathrm{Fe}_{2} \mathrm{O}_{3}$ in the ash may play a role for the interaction between the molten coal ash and the coke.
$\mathrm{O}_{2}$ ratio $: 1.2, \mathrm{O}_{2}$ vol\% $: 21$, Vitiated air temp. : $1500 \mathrm{~K}$

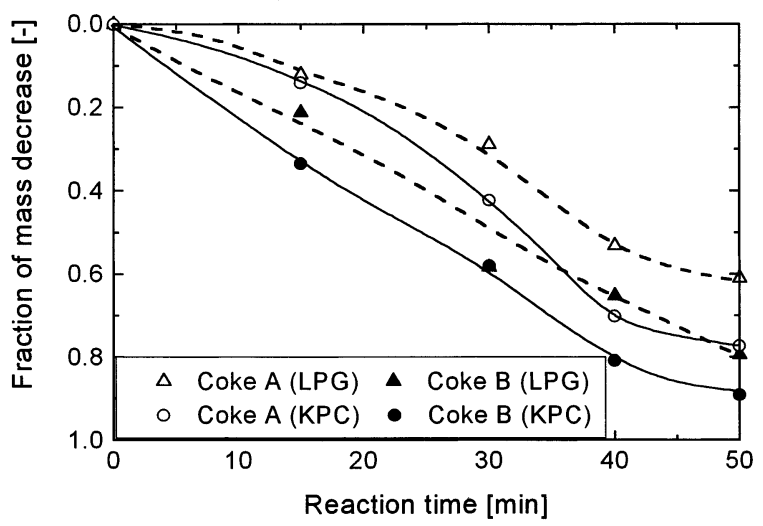

Fig. 8. Fraction of mass decrease of coke lump during the reaction.

\section{$\mathrm{O}_{2}$ ratio : $1.2, \mathrm{O}_{2}$ vol\%: 21 , Vitiated air temp. : $1500 \mathrm{~K}$}

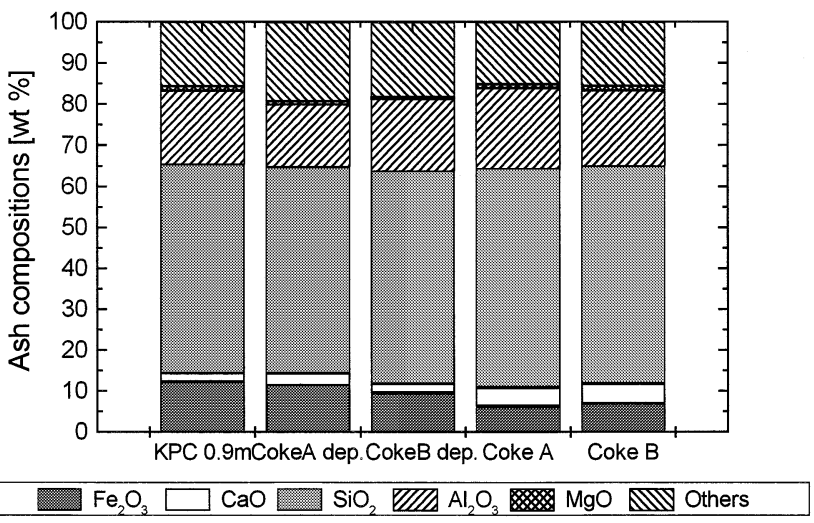

Fig. 9. Ash compositions of deposition on the coke surface, reacting particles and both the cokes.

This result suggests that the molten coal ash may contribute to the coke reaction, even if the surface temperature of coke for the LPG combustion is higher than that for the coal combustion as shown in Fig. 5. Besides, water vapor concentration for the coal combustion is lower than that for the LPG combustion although $\mathrm{CO}_{2}$ concentration indicates the opposite tendency from the water vapor concentration, as shown in Figs. 2 and 3.

\subsection{Changes of Ash Components}

Under the high temperature conditions that the particle temperature exceeds about $2250 \mathrm{~K}$ a portion of coal ash components is molten. A part of those molten particles collides with the coke at the surface.

In order to confirm whether the molten coal ash deposited on the coke surface or not, the material deposited was analyzed by the Furnace-AA. The ash composition obtained is shown in Fig. 9, comparing with that in burning particles sampled at $0.9 \mathrm{~m}$ and both the coke ashes. As seen from this figure, the ash compositions of deposition on the coke surface are almost similar with those in the burning particles, but are different from those in the coke. Therefore, the molten material depositing on the coke surface is originated from the coal. This result suggests that the ash deposition of coal enhances the coke reaction due to chemical interaction between coal ash and coke. 


\section{Conclusions}

Reaction and/or degradation behaviors of coke lump in raceway of blast furnaces with pulverized coal injection technology were studied by using a horizontal pulverized coal reactor with a pre-combustor. The results obtained are summarized as follows:

(1) In the coal combustion volatile matter is rapidly evolved under the condition that the particle temperature exceeds about $2250 \mathrm{~K}$.

(2) The molten material on the coke surface for the coal combustion is larger than that for the LPG combustion. The collision and deposition of molten coal ash cause it.

(3) The molten coal ash enhances coke reaction and/or degradation due to chemical interaction between coal ash and coke.

\section{REFERENCES}

1) M. Shimizu: Research Group of Pulverized Coal Combustion in Blast Furnace-1, JSPS54, (1995).

2) S. Inaba: Nishiyama Memorial Lecture, ISIJ, Tokyo, (1993), 203.

3) K. Shibata, K. Nozawa, M. Shimizu, R. Ono, T. Okuda and R. Ito: CAMP-ISIJ, 6 (1993), 112.

4) Y. Iwanaga and T. Inada: Research Group of Pulverized Coal Combustion in Blast Furnace, Rep-12, (1993).
5) F. Shen, T. Inada, K. Yamamoto and Y. Iwanaga: Tetsu-to-Hagané, 80 (1994), 7.

6) H. Kugisaki, K. Ohshima, I. Naruse and K. Ohtake: CAMP-ISIJ, 9 (1996), 6.

7) A. S. Jamaluddin, T. F. Wall and J. S. Truelove: Proc. of the $21 \mathrm{st}$ Symp. (Int.) on Combust., The Combustion Institute, Pittsburgh, (1986), 575.

8) T. Sugiyama and M. Sugata: Seitetsu Kenkyu, 325 (1987), 34.

9) K. Takatani, T. Inada and Y. Ujisawa.: CAMP-ISIJ, 7 (1994), 50.

10) H. Tsuge, T. Yoshida, H. Aoki, and T. Miura: Proc. of the 25th Symposium (Int.) on Combustion, The Combustion Institute, Pittsburgh, (1994), 493.

11) K. Kadoguchi, T. Goto, R. Ito , T. Yabata and M. Shimizu: Kobe Steel Eng. Rep., 46 (1996), 2.

12) P. R. Austin, H. Nogami and J. Yagi: ISIJ Int., 37 (1997), 458.

13) Y. Ishikawa, M. Kase, Y. Abe, K. Ono, M. Sugata and T. Nishi: AIME Iron making Proc., 42 (1983), 357.

14) H. Haraguchi, T. Nishi, Y. Miura, Y. Ushikubo and T. Noda: Tetsuto-Hagané, 70 (1984), 2216.

15) T. Tsukuji, M. Hattori, A. Yamaguchi, A. Shimomura, K. Ishii and S. Itagaki: CAMP-ISIJ, 6 (1993), 892.

16) K. Yamaguchi, T. Uno, T. Yamamoto, H. Ueno, Y. Konno and S. Matsuzaki: Tetsu-to-Hagané, 82 (1996), 641.

17) A. Kasai, K. Miyakawa, T. Kamijyo, K. Kiguchi and M. Shimizu: Tetsu-to-Hagané, 83 (1997), 239.

18) R. Noda, I. Naruse, and K. Ohtake: J. Chem. Eng. Jpn., 29 (1996), No. 2, 235 